\title{
Segmental and suprasegmental properties in nonword repetition: An explorative study of the associations with nonword decoding in children with normal hearing and children with bilateral cochlear implants
}

\author{
Cecilia Nakeva von Mentzer, Björn Lyxell, Birgitta Sahlén, Örjan Dahlström, Magnus \\ Lindgren, Marianne Ors, Petter Kallioinen, Elisabet Engström and Inger Uhlén
}

\section{Linköping University Post Print}

\section{Tweet}

N.B.: When citing this work, cite the original article.

Original Publication:

Cecilia Nakeva von Mentzer, Björn Lyxell, Birgitta Sahlén, Örjan Dahlström, Magnus Lindgren, Marianne Ors, Petter Kallioinen, Elisabet Engström and Inger Uhlén, Segmental and suprasegmental properties in nonword repetition: An explorative study of the associations with nonword decoding in children with normal hearing and children with bilateral cochlear implants, 2014, Clinical Linguistics \& Phonetics.

http://dx.doi.org/10.3109/02699206.2014.987926

Copyright: Informa Healthcare

http://informahealthcare.com/

Postprint available at: Linköping University Electronic Press

http://urn.kb.se/resolve?urn=urn:nbn:se:liu:diva-108901 


\begin{abstract}
The present study explored nonword repetition (NWR) and nonword decoding in normalhearing $(\mathrm{NH})$ children and in children with bilateral cochlear implants (CI). Participants were eleven children with $\mathrm{CI}, 5: 0-7: 11$ years $(\mathrm{M}=6.5 \mathrm{yrs}$.), and eleven $\mathrm{NH}$ children, individually age-matched to the children with CI. The present study fills an important gap in research, since it thoroughly describes detailed aspects of nonword repetition and nonword decoding and their possible associations. All children were assessed after having practiced with a computerassisted reading intervention with a phonics approach during four weeks. Results showed that $\mathrm{NH}$ children outperformed children with CI on the majority of aspects of NWR. The analysis of syllable number in NWR revealed that children with CI made more syllable omissions than did the NH children, and predominantly in prestressed positions. Additionally, the consonant cluster analysis in NWR showed significantly more consonant omissions and substitutions in children with CI suggesting that reaching fine- grained levels of phonological processing was particularly difficult for these children. No significant difference was found for nonworddecoding accuracy between the groups, as measured by whole words correct and phonemes correct, but differences were observed regarding error patterns. In children with CI phoneme deletions occurred significantly more often than in children with $\mathrm{NH}$. The correlation analysis revealed that the ability to repeat consonant clusters in NWR had the strongest associations to nonword decoding in both groups. The absence of as frequent significant associations between NWR and nonword decoding in children with CI compared to children with $\mathrm{NH}$, suggest that these children partly use other decoding strategies to compensate for less precise phonological knowledge, for example, lexicalizations in nonword decoding, specifically, making a real word of a nonword.
\end{abstract}

Keywords: nonword repetition, nonword decoding, children, normal hearing, cochlear implants

\title{
Introduction
}

A large number of studies have explored how phonological processing skills relate to decoding in reading in typically developing children as well as in clinical populations, for example in children with dyslexia and in children with specific language impairment, SLI (Aro et al., 1999; Conant, Liebenthal, Desai, \& Binder, 2013; Melby-Lervåg, Lyster, \& Hulme, 2012; Nash, Hulme, Gooch \& Snowling, 2013; Puolakanaho et al., 2007, 2008; Ramus, 2001; Ramus \& Szenkovits, 2008; Talcott, Witton, \& Stein, 2013). In the early stages of reading acquisition phonological decoding is essential (Frith, 1985; Share, 1995). One core aspect in phonological 
decoding is the ability to use fine-grained units (phonemes and graphemes) to decode novel words, which enable children to autonomously acquire an orthographic lexicon (Share, 1995). Consequently, besides phonological processing skills, letter knowledge has been shown to be of considerable importance in beginning reading development (Hulme, Bowyer-Crane, Carroll, Duff, \& Snowling, 2012; Näslund \& Schneider, 1996). As children grow older and become more experienced readers, orthographic decoding, that is, automatic recognition of familiar words, contributes to reading fluency and speed (for dual-route models of reading, see Stanovich, 2000). Thus, to become an efficient reader, the phonological (indirect) route must be used flexibly together with the orthographic (direct) route. In the present study, aspects of phonological processing skills, phonological decoding, and their associations will be investigated in $\mathrm{NH}$ children and in deaf and hard of hearing (DHH) children using bilateral cochlear implants (CI).

A large bulk of research has shown that nonword repetition (NWR) is predictive of language development and also a clinical marker of language impairment, LI (Baddeley, 1998; Coady \& Evans, 2008; Gathercole, 2006). Recently, high sensitivity and specificity was shown for Swedish children with SLI and a relationship between NWR and familial aggregation of language and reading related problems (Kalnak, Peyrard-Janvid, Sahlén \& Forssberg, 2014). Essentially, NWR is considered a phonological processing task that aims to measure phonological working memory, WM (Baddeley, 1998; Carter, Dillon, \& Pisoni, 2002). Many researchers have, however, claimed that a range of cognitive and linguistic skills are needed to repeat a novel word, for example discrimination of phonemes, output phonology and oromotor skills (Coady \& Evans, 2008; Dillon, Cleary, Pisoni, \& Carter, 2004; Ibertsson, WillstedtSvensson, Radeborg, \& Sahlen, 2008; Krishnan et al., 2013; Rispens \& Baker, 2012). Thus, NWR is considered to capture a range of phonological processing skills and may not be a simple index of phonological WM in children (Sahlén et al, 1999b).

Several researchers have stressed the need of in-depth analyses of both segmental and suprasegmental (i.e. prosodic) aspects in NWR in children with CI (Carter et al., 2002; Dillon et al., 2004; Ibertsson et al., 2008). Ibertsson et al. argued that the use of a combined measure could help clinicians to identify children with CI who do not develop language as expected, as they could be at risk for LI. Recently, Casserly and Pisoni (2013) appreciated the use of longitudinal assessment of NWR for this purpose. In their study on children with CI 8-9 years of age, NWR proficiency predicted language performance ten years later. In several studies (using different sets of nonwords with similar phonological complexity as in the present study) children with $\mathrm{CI}$ have been found to be much less accurate than $\mathrm{NH}$ children regarding 
segmental aspects (Dillon et al., 2004; Ibertsson et al., 2008). Higher proficiency is usually to be expected for suprasegmental aspects, suggesting that children with CI are relatively better at both encoding and repeating the overall prosodic envelope (syllable number and stress) in nonwords than segmental properties (Asker- Árnason, Wass, Ibertsson, et al., 2007; Carter et al., 2002; Dillon et al., 2004; Ibertsson et al., 2008).

Prosodic characteristics of the ambient language seem to influence repetition of words and nonwords in NH children (Yuzawa \& Saito, 2006) and in children with LI (Sahlén et al., 1999a). In Anglo-Saxon languages, for example German, English, Danish, Norwegian, and Swedish (Bosworth, 1838) there is a so-called trochaic bias. Accordingly, children are less prone to omit weak syllables in words with trochaic (strong-weak) patterns (Leonard, 2000; ReuterskiöldWagner, Sahlén \& Nyman, 2005). The metric hypothesis thus postulated a greater vulnerability for weak syllables in pre-stressed than in post-stressed positions in children with typical language development and NH and in children with SLI (Carter \& Gerken, 2003; Gerken, 1994). Sahlén et al. (1999a) for example found that in NWR, children with LI omitted weak syllables in pre-stressed positions six times more often than in post-stressed positions in the nonwords. Further, Carter et al. (2002) found a similar syllable repetition pattern for both children with $\mathrm{CI}$ and $\mathrm{NH}$ children, which manifested itself as a higher proficiency for nonwords with primary stress on the first syllable and as an overall tendency to omit syllables more often than to add syllables. An additional aspect to consider is the production and repetition of consonant clusters. Here, children with CI have been reported to have similar developmental stages and reduction patterns as $\mathrm{NH}$ children for initial consonant cluster acquisition in picture naming and spontaneous speech (Adi-Bensaid \& Ben-David, 2010). In the present study, besides segmental aspects, two prosodic characteristics of NWR will be investigated: stress pattern and syllable number. The concepts 'suprasegmental' and 'prosodic' will be used interchangeably throughout the study. Further, an important gap in research will be closed, as an analysis of children's repetition proficiency of consonant clusters in nonwords also will be performed.

Knowledge of the association between phonological processing skills and phonological decoding in reading is relatively sparse in DHH children. However, studies have investigated aspects of reading development in children with CI. Geers (2003) for example, examined decoding skills and reading comprehension and demonstrated that half of the children with CI in elementary school (8-9 years of age) showed comparable levels to their NH peers. When assessing the same children in secondary school at 15-16 years of age (Geers et al., 2008), children with CI showed a relatively slower pace on all aspects of reading development when 
compared to other skills. Further, Dillon \& Pisoni (2001, 2006) conducted a series of studies on NWR and nonword decoding in a subsample of children with CI who took part in the earlier study by Geers (2003). Dillon \& Pisoni found that the children could complete the nonworddecoding task, that NWR performance and nonword decoding was significantly correlated, thus indirect comparisons were made between the tasks. Further, the authors found that $>70 \%$ of the children achieved total reading scores (sight word reading and reading comprehension) that were in the normal range of $\mathrm{NH}$ children. However, up till now, no earlier study has performed an in-depth analysis of NWR as well as of nonword decoding (i.e. cluster analysis and error decoding strategies), and their possible direct correlations in DHH children using bilateral CI or in children with NH. Additionally, this gap in research comprehends both English and Swedish speaking children.

Given their relatively poor phonological processing skills researchers have sometimes claimed that children with CI read better than what can be expected (Asker-Árnason, Wass, Gustavsson, et al., submitted, 2014; Wass et al., 2010). This pattern has also been demonstrated in studies of children with mild to moderate hearing loss, HL (Park, Lombardino, \& Ritter, 2013). The question then arises whether children with CI use other reading strategies to make up for poor phonological processing skills. There is a possibility that they use the orthographic route more frequently than the phonological route to word recognition. These alternate reading strategies have been observed in other clinical populations. For example, adult resilient readers were observed to compensate for poor phonological decoding skills via greater reliance on word meaning relationships in the study by Welcome, Leonard and Chiarello (2010). Further, Park et al. (2013) suggested that children with mild-to-moderate sensorineural HL compensate for poor phonological processing skills by building up rich orthographic (visual) word lexicons, which may explain the relatively higher proficiency in word decoding reported. When performing nonword-decoding tasks phonological decoding is of considareble importance. Thus, the reader must be able to make efficient translations of graphemes to phonemes, via the sub-lexical phonological route, as there are no lexical representations of nonwords (Nakeva von Mentzer, Lyxell, Sahlén, et al., 2014; Stanovich, 2000; Ziegler et al., 2008). Consequently, nonword decoding may be particularly difficult for DHH children using CI since it challenges the access to sub-lexical phonological representations, which in many of these children have been observed to be less specified (Wass et al., 2008).

The present study is an explorative study of nonword repetition and nonword decoding in Swedish children with bilateral CI and NH children, age matched to the children with CI. All children had participated in a computer-assisted reading intervention with a phonics approach 
thus; the assessment took place at post intervention. The study had three purposes. First, was to scrutinize segmental and suprasegmental aspects as well as consonant cluster production in nonword repetition. Second, to examine fine-grained aspects of nonword decoding including error patterns. Third, was to analyse the associations between nonword repetition and nonword decoding in both groups.

\section{Method}

\section{Participants}

Eleven children (nine girls) with CI 5:0-8:01 years of age ( $M=6.5$ years) took part in the study. Eleven NH children (five girls) 5:0-7:10 years of age ( $M=6.5$ yrs.), were individually agematched to the children with CI ( \pm 2 months, range $0-6$ ), and served as a comparison group. All children had scores in the normal range of non-verbal intelligence as measured by performance on Raven's coloured matrices (range $50-95^{\text {th }}$ percentile) test. The study was approved by the Regional Committee for Medical Research Ethics in Stockholm, Sweden. For demographics of all participants see Table 1.

\begin{tabular}{|c|c|c|c|c|c|c|c|c|c|c|c|c|}
\hline Participant & $\mathrm{NH}$ & $\begin{array}{l}\text { Age at } \\
\text { testing }\end{array}$ & Raven & $\mathrm{CI}$ & $\begin{array}{l}\text { Age at } \\
\text { testing }\end{array}$ & Raven & $\begin{array}{l}\text { Age at } \\
\text { diagnosis }\end{array}$ & $\begin{array}{l}\text { Age at } \\
\text { implant }\end{array}$ & $\begin{array}{l}\text { Time } \\
\text { with CI }\end{array}$ & CI right & CI left & $\begin{array}{l}\text { Processing } \\
\text { Strategy }\end{array}$ \\
\hline 1 & F & 91 & 95 & F & 91 & 75 & 2 & 11 & 80 & $\mathrm{C}_{40+}$ & Pulsar & FSP \\
\hline 2 & F & 92 & 90 & F & 92 & 95 & 9 & 13 & 79 & $\mathrm{C}_{40+}$ & Pulsar & FSP \\
\hline 3 & M & 60 & 95 & $\mathrm{~F}$ & 62 & 75 & 19 & 23 & 39 & Pulsar & Sonata & FSP \\
\hline 4 & M & 79 & 75 & M & 75 & 75 & 12 & 19 & 60 & Pulsar & Pulsar & FSP \\
\hline 5 & $\mathrm{~F}$ & 73 & 50 & M & 73 & 95 & 19 & 21 & 52 & Pulsar & Pulsar & FSP \\
\hline 6 & M & 75 & 75 & $\mathrm{~F}$ & 73 & 95 & 9 & 12 & 63 & $\mathrm{CI} 24 \mathrm{RE}$ & CI2ARE & $A C E$ \\
\hline 7 & $\mathrm{~F}$ & 88 & 95 & F & 82 & 75 & 18 & 39 & 49 & $C I 24 R E$ & CI2ARE & $\mathrm{ACE}$ \\
\hline 8 & M & 67 & 95 & F & 65 & 90 & 1 & 8 & 60 & Pulsar & Pulsar & FSP \\
\hline 9 & $\mathrm{M}$ & 84 & 95 & F & 84 & 95 & 18 & 22 & 61 & Pulsar & Pulsar & FSP \\
\hline 10 & M & 68 & 95 & F & 64 & 75 & 2 & 36 & 32 & Sonata & Sonata & FSP \\
\hline 11 & $\mathrm{~F}$ & 94 & 95 & F & 95 & 50 & 8 & 12 & 82 & $\mathrm{CI} 24 \mathrm{R}(\mathrm{CS})$ & CI24RE & $A C E$ \\
\hline Mean & & 79 & 90 & & 78 & 81 & 10 & 20 & 60 & & & \\
\hline
\end{tabular}

Note: $\mathrm{NH}=$ normal hearing, $\mathrm{CI}=$ cochlear implants, $\mathrm{F}=$ female, $\mathrm{M}=$ male, mo $=$ months, $\mathrm{C} 40+=$ Med-El, Sonata $\mathrm{T} 1100=$ Med-El, CD24RE $=$ Cochlear Nucleus, FSP = Fine Structure Processing, ACE = Advanced Combination Encoder

Children with CI The aetiology of HL was hereditary in seven of the children (1 child had Jervell and Lange-Nielsen syndrome) and unknown in three. Cytomegalovirus was the cause of the known non-hereditary HL. All children had used their CI for at least 32 months $(M=60$, $S D=16.3$ ). Mean age at diagnosis was 10 months (range 1-19). Mean age at implant was 20 
months (range 8-39). Seven of the children were prelingually deaf (diagnosed before 12 months of age). Mean age at testing was 78 months (range 62-95). All children with CI were, as is routine in Sweden, fitted with bilateral conventional hearing aids after the diagnosis of HL and prior implantation. The inclusionary criteria for children with CI were that they should use spoken language in their educational setting. Nine children were educated in a mainstream school and used spoken language as the main communication mode at school and at home. One child used sign language at home and went to a preschool for DHH children where a combination of signed and spoken language was used. One child used sign to support her spoken language. That child spent the majority of the time in a mainstream school and went to a special school for DHH children for a couple of weeks each semester.

Children with normal hearing The inclusionary criteria for the comparison group was normal hearing ascertained by performance at the regular hearing screening at four years of age, and confirmed by their parents in a written consent form. All of the children used Swedish in their educational setting. One child used another spoken language besides Swedish at home (fluent in Swedish and English).

\section{Procedure}

All children but one were assessed in a soundproof room at the department of Linguistics, Stockholm University by a Speech language pathologist (SLP.) One child was assessed at the Department of Logopedics, Phoniatrics and Audiology, Lund University hospital by another SLP. Both SLPs had extensive experience of testing children with HL and had used the tests earlier in the clinic. Test procedures were reviewed at the onset of the study. Thus, the first author presented the test procedure, the test order, and instructions to the second SLP who were able to ask questions. All children had participated in a computer-assisted reading intervention study with a phonics approach (Nakeva von Mentzer et al., 2013) with three test points (baseline, pre intervention and post intervention) with four weeks in between. Tests analysed in the present study took place post-intervention to enable an analysis of the children's performance in relation to possible effects of the intervention. For more detailed information about the test procedure, see Nakeva von Mentzer et al. (2013).

The Nonword repetition task is from a computer-based test battery called the SIPS (Sound Information Processing System; Wass et al., 2008). The nonwords were presented through two external loudspeakers (Logitech) with a presentation level at approximately 60-65 dB hearing level. Comfortable presentation level and audition were secured for the participants in two ways. For children with CI the child and the parent were first asked whether the CI was working 
properly. Second, both NH children and children with CI were asked to listen and repeat what he/she heard when presented with two initial sentences in the Sentence Repetition task, also from the SIPS (Wass et al., 2008). The presentation level was adjusted according to the child's answer; namely, when the child expressed that he/she found it hard to hear, the volume was increased to ensure a comfortable level of audibility for each individual child.

Nonword repetition. The nonword repetition task (SIPS; Wass et al., 2008) was used to assess phonological skills. In this task, the children were asked to repeat 24 individual three to foursyllable nonwords after a single auditory-only presentation as well as they could. The children's performance was audio-recorded. The nonwords contained a total of 120 consonants, 84 vowels and 16 clusters. The nonwords were balanced for syllable number, stress pattern, legal and illegal clusters. All consonant clusters occurred in the stressed syllable. Ten of the clusters had two consonants (CC) and 6 of the clusters had three (CCC), see Table 2.

\begin{tabular}{|c|c|c|c|c|c|c|c|c|c|c|}
\hline & \multirow[t]{2}{*}{ Nr. of NW } & \multirow[t]{2}{*}{ Nr. of syllables } & \multicolumn{2}{|c|}{ Weak syllables } & \multirow[t]{2}{*}{ Cons. } & \multirow[t]{2}{*}{ Vow. } & \multicolumn{2}{|c|}{ Stress pattern } & \multicolumn{2}{|c|}{ Clusters } \\
\hline & & & Prestressed & Post-stressed & & & Iamb & Trochee & Legal & Illegal \\
\hline & 12 & 3 & 12 & 12 & 53 & 36 & 6 & 6 & 4 & 4 \\
\hline & 12 & 4 & 18 & 18 & 67 & 48 & 6 & 6 & 4 & 4 \\
\hline Total & 24 & 84 & 30 & 30 & 120 & 84 & 12 & 12 & 8 & 8 \\
\hline
\end{tabular}

Note: $\mathrm{Nr}$. $=$ number, $\mathrm{NW}=$ nonwords, Cons. $=$ consonants, Vow. $=$ vowels

The nonwords were categorized into nonwords with no clusters, nonwords with legal clusters and nonwords with illegal clusters. Illustrations of Swedish legal cluster in initial position are for example a fricative followed by a plosive and a tremulant, /str/ or a plosive followed by a labiodental, /kv/, in initial position. Correspondent illustration of illegal clusters are for example two plosives in initial position, /pt/, or a fricative, followed by a nasal and a liquid, /sml/ in initial or final position. For all nonwords used in the present study see Appendix.

Scoring and analytic procedure of the nonword repetition task

The first level of analysis was the whole-word score. Here, the child received a score of 1 if no alteration of the phonological structure was made, (e.g., "drallabelli” -> [bralabeli] received a 
score of zero). Then, the scoring followed the procedure as reported by Wass et al. (2008, eg. percent consonants correct, PCC). Prior researchers' recommendation to include both segmental and suprasegmental levels of analysis was also considered (e.g. Ibertsson et al, 2008). Thus, PCC, percent vowels correct, PVC and syllable insertions was calculated separately for each nonword category (see above). Additionally, syllable omissions were calculated in relation to the stress pattern of the nonword (pre- and post stressed position). Further, to receive more precise information regarding phonological processing in children with CI, a cluster analysis was performed. Here, four categories were established: consonant omissions (e.g./spj/ -> [sp]), consonant substitutions (e.g. /str/ $\rightarrow$ [spr]), vowel epentheses (e.g. /sml/ $\rightarrow$ [sməl]), and consonant additions (e.g. /nt/ -> [nts]).

For an overview, see Table 3.

Table 3. Scoring and levels of analysis for the nonword repetition task

\begin{tabular}{|c|c|c|c|}
\hline Whole word & Segmental & Suprasegmental & Consonant clusters \\
\hline $\begin{array}{l}\text { Percent nonwords } \\
\text { correct, } \\
(\max 24)\end{array}$ & $\begin{array}{l}\text { Percent consonants } \\
\text { correct, pcc } \\
(\max 120)\end{array}$ & $\begin{array}{l}\text { Percent } \\
\text { omissions; } \\
\text { Pre- and post stressed } \\
\text { positions } \\
(\max 30 \mathrm{pre} / \text { post) }\end{array}$ & $\begin{array}{l}\text { Percent legal and illegal } \\
\text { clusters correct } \\
\text { (max } 88 \text { each) }\end{array}$ \\
\hline & $\begin{array}{l}\text { Percent vowels } \\
\text { correct, pvc } \\
(\max 84)\end{array}$ & $\begin{array}{l}\text { Number of } \begin{array}{r}\text { syllable } \\
\text { insertions for }\end{array} \text { each } \\
\text { nonword category }\end{array}$ & $\begin{array}{l}\text { Number of } \\
\text { Consonant omissions } \\
\text { Consonant substitutions } \\
\text { Vowel epentheses } \\
\text { Consonant additions }\end{array}$ \\
\hline & $\begin{array}{l}\text { Percent phonemes } \\
\text { correct, } \\
(\max 204)\end{array}$ & $\begin{array}{l}\text { Percent syllable number } \\
\text { correct } \\
(\max =24)\end{array}$ & \\
\hline & $\begin{array}{l}\text { Pcc for each } \\
\text { nonword category; } \\
(\max 31 / 44 / 45)\end{array}$ & $\begin{array}{l}\text { Percent primary stress } \\
\text { correct } \\
(\max 24)\end{array}$ & \\
\hline & $\begin{array}{l}\text { Pvc for each } \\
\text { nonword category; } \\
\text { (max } 28 \text { each) }\end{array}$ & & \\
\hline
\end{tabular}

The Test of Word Reading Efficiency (TOWRE; Torgesen, Wagner \& Rashotte, 1999, Swedish version by Byrne et al., 2009) was used to assess phonological decoding of nonwords. The child was required to read aloud as many nonwords as fast and as accurately as possible in $45 \mathrm{sec}$. The children's performance was audio-recorded. TOWRE consists of 126 (nonwords) and 601 (phonemes) presented in two lists, A and B. The spelling to sound regularity is transparent in 
$96 \%$ of the cases (i.e. when a phoneme corresponds to a single grapheme). Exceptions were /n/ which was orthographically notified with a bigraph "ng" or a single $/ \mathrm{n} /, \quad / \int /$ which was notified with the bigraphs "sh", "rs" and "ch", or the trigraphs "sch" and "skj", and finally notations with a double consonant succeeding vowels with a short duration (e.g. " $\mathrm{tt}$ " in "kratti" /kratı/, or "ck" for double /k/). Consonant-clusters occur after the child has read 16 nonwords in list A and 18 nonwords in list $\mathrm{B}$. Thus, many beginning readers do not reach that difficulty level due to running out of time. The nonwords in the nonword decoding-task are not balanced in the same way as in the nonword repetition task. Therefore, corresponding segmental and suprasegmental analyses could not be conducted. However, a correspondent analysis was made of the children's decoding of transparent nonwords without and with clusters.

Scoring and analytic procedure of the nonword-decoding task

The nonword-decoding task was scored and analyzed in six ways. Further explanation of the analytic procedure is provided below.

Whole words — Percent nonwords correctly decoded.

Phonemes - Percent phonemes correctly decoded.

Trials - Percent nonword-decoding trials (correct and incorrect).

Clusters - Percent orthographically transparent nonwords correctly decoded: nonwords with no clusters, and nonwords with clusters.

Errors - Percent nonword decoding errors out of nonword decoding trials.

Nonword decoding errors were categorized in four categories: number of phoneme insertions, phoneme deletions, phoneme substitutions and lexicalization (i.e. making a real word of the target nonword).

Vowel quality was scored according to the following for nonwords with CV - or CVC structure, for example, "ba" received a score of 1 when pronounced [ba] or [ba], "bat" received a score of 1 when pronounced [bat] or [bat]. For nonwords where the vowel was followed by a double consonant for example, "kratti", only [kratı] not [kratr] received a score of 1 following the orthographic rules in Swedish. Orthographic knowledge of bigraphs (eg. "ng" pronounced as $/ \mathrm{y} /$ ) and trigraphs (eg. "skj” pronounced as $/ \mathrm{g} /$ ) received a score of 1 . If the child decoded these as two or three separate sounds a score of zero was given.

In order to capture children's decoding strategies more explicitly two additional measures were included. These were percent nonword decoding trials and percent nonword decoding errors in 
relation to trials. In the trial score correctly and incorrectly decoded nonwords were included. The rationale for this was that the trial score gave an estimate about the decoding speed, (eg. how much of the nonword-decoding task the child completed in 45 seconds). Further, it enabled to better differentiate between children reaching similar phoneme scores. For example, child 2 (CI) who accurately decoded 13 percent of the phonemes, made attempts to read out 42 nonwords in $45 \mathrm{sec}$. Out of these, 27 nonwords were incorrect (64\%). The age-matched NH peer also decoded 13 percent of the phonemes correct but only attempted to read out 37 nonwords, and out of these, only 18 were incorrect (49\%). Finally, we analysed the influence of orthographically transparent nonwords' phonological complexity on children's nonword decoding ability, namely, decoding accuracy of nonwords with no clusters and nonwords with clusters.

\section{Letter knowledge}

A composite score was computed based on performance in three letter tasks; recognition (matching phonemes and letter names to graphemes) and naming of lower case letters.

For a detailed description of the test procedure, see Nakeva von Mentzer et al. (2013).

\section{Inter-rater reliability}

The first author scored all the data from both tests. Inter-rater reliability was measured on 20 percent (four children; two with $\mathrm{NH}$ and two with $\mathrm{CI}$ ) of the transcriptions of PCC and PVC in the Nonword repetition task (total scores and separately for the three categories of nonwords; no clusters, legal clusters and illegal clusters). This was measured with Pearson's correlation coefficient between the transcriptions made by the first author and by two SLPs. The inter-rater reliability between the two SLPs together and the first author was at least $r=.95$ for the total scores of PCC and PVC. For PCC in the three categories the following correlations were obtained; $r=1.0$ (no clusters and legal clusters) and $r=.98$, (illegal clusters), and for PVC; $r$ $=.95$, (no clusters), and $r=.98$, (legal and illegal clusters), $p<.05$ for all correlations.

Additionally, the first author and a second SLP scored the nonword-decoding task for two children (one NH child and one child with $\mathrm{CI}$ ). Totally decoded phonemes for these children were 107. The SLPs agreed upon 106 of these.

\section{Statistical analysis}

Considering the small sample size all data was analysed using non-parametric statistics. Group comparisons were made using the Mann Whitney U-test, thus median scores were compared. 
Correlational analyses were conducted using Spearman's correlation coefficient. P-values $<.05$ were considered significant.

\section{Results}

Nonword repetition task

Overall group comparisons

Children with NH significantly outperformed children with CI on the majority of segmental and suprasegmental aspects of NWR, see Table 4. The largest difference was found for the whole-word score; NH $(M d n=54.0 \%), \mathrm{CI}(M d n=4.2 \%), \mathrm{U}=.00, \mathrm{z}=-3.99, p<.001, r=.85$. As for suprasegmental levels, the smallest difference was obtained on correct primary stress; $\mathrm{NH}(M d n=100 \%), \mathrm{CI}(M d n=83.3 \%), \mathrm{U}=13.0, \mathrm{z}=-3.21, p<.001, r=.68$. Further, both groups of children reproduced vowels significantly more accurate than they reproduced consonants (for example children with CI, vowels; $M d n=69.0 \%$ vs. consonants; $M d n=$ $53.0 \%)$. 
Table 4. Nonword repetition (medians, $\min$ and $\max$ ) in percent in $\mathrm{NH}$ children $(N=11)$ and in children with $\mathrm{CI}(N=11)$

\begin{tabular}{lll}
\hline & NH & CI \\
\hline Whole words & $54.0(25.0-71.0)$ & $4.2^{1}(0-12.5)$ \\
Segmental & & \\
\hline Consonants & & \\
Total & $85.0(67.0-95.0)$ & $53.0^{1}(23.0-72.5)$ \\
Nonwords (no clusters) & $93.5(80.7-100)$ & $61.3^{1}(25.8-83.9)$ \\
Nonwords (legal clusters) & $88.6(72.7-100)$ & $59.1^{1}(20.5-93.2)$ \\
Nonwords (illegal clusters) & $75.6(44.4-88.9)$ & $40.0^{1}(24.4-48.9)$ \\
Vowels & & \\
Total & $95.2(84.5-98.8)$ & $69.0^{1}(32.1-86.9)$ \\
Nonwords (no clusters) & $96.4(85.7-100)$ & $64.3^{1}(32.1-85.7)$ \\
Nonwords (legal clusters) & $96.4(89.3-100)$ & $78.6^{1}(35.7-96.4)$ \\
Nonwords (illegal clusters) & $89.3(64.3-100)$ & $67.9^{1}(25.0-89.3)$ \\
Suprasegmental & & \\
Syllable number & & $79.2^{1}(33.3-95.8)$ \\
Primary stress & $100(87.5-100)$ & $83.3^{1}(54.2-95.8)$ \\
Consonant clusters & $100(91.7-100)$ & \\
Legal correct & & $50.0^{1}(0-100)$ \\
\hline Illegal correct & $100(75.0-100)$ & $0^{2}(0-62.5)$ \\
\hline
\end{tabular}

Note: $\mathrm{NH}=$ normal hearing, $\mathrm{CI}=$ cochlear implants.

$1=p<.001,{ }^{2}=p<.05$

Suprasegmental analysis

Changes of syllable number in the NWR task - Omissions

There were 60 weak syllables in total in the NWR-task, equally distributed in the pre-stressed and post-stressed positions of the nonwords. Syllables omissions occurred in total 40 times. Children with CI made $95 \%$ of the omissions. Sixty-three percent of these occurred in prestressed position and $37 \%$ occurred in post-stressed position.

Omissions made by NH children occurred only in post-stressed position. 
Changes of syllable number in the NWR task - Insertions

Insertions totally occurred totally 22 times (also represented as vowel epentheses in the cluster analysis). Children with CI made the majority of these ( $73 \%$ in total). Insertions were equally distributed among the children in the CI-group: all children but one made insertions. In the $\mathrm{NH}$ group, five children made insertions. Three of the children who made the insertions were the youngest in the NH group. Generally, in all children, insertions occurred more often in nonwords with illegal clusters (86\% of all clusters) than in nonwords with no clusters or nonwords with legal clusters, see Table 5.

Table 5. Number of syllable insertions in the nonword repetition task

\begin{tabular}{|lllll|}
\hline & No clusters & Legal clusters & Tllegal clusters & Total \\
\hline $\mathrm{NH}$ & 1 & 1 & 4 & 6 \\
$\mathrm{CI}$ & 1 & 0 & 15 & 16 \\
\hline
\end{tabular}

Note: $\mathrm{NH}=$ normal hearing, $\mathrm{CI}=$ cochlear implants

Consonant cluster analysis

Figure 1 shows the consonant cluster analysis. Children with NH reproduced 82 out of $88(93 \%)$ legal consonant clusters correct compared to children with CI who repeated 42 correct (48\%); $\mathrm{NH}(M d n=8.00), \mathrm{CI}(M d n=4.00), \mathrm{U}=8.5, \mathrm{z}=-3.55, r=.76$. For illegal clusters children with NH repeated 24 correct (27\%) compared to children with CI who repeated 7 correct (8\%). These comparisons revealed a statistically significant difference, see Table 4.

It should be noted that in the CI-group child 3 and 6 repeated six (75\%) vs. eight (100\%) of the legal consonant clusters correct, thus, performing at a comparable level as the NH children. The successive categorisation showed that two out of six categories occurred significantly more often in children with CI compared to children with NH. These were consonant omissions in legal consonant clusters; $\mathrm{NH}(M d n=.00), \mathrm{CI}(M d n=3.00), \mathrm{U}=11.5, \mathrm{z}=-3.40, p<.001, r=$ .72 , and consonant substitutions in legal consonant clusters; $\mathrm{NH}(M d n=.00), \mathrm{CI}(M d n=1.00)$, $\mathrm{U}=22.0, \mathrm{z}=-2.85, p<.001, r=.61$. 


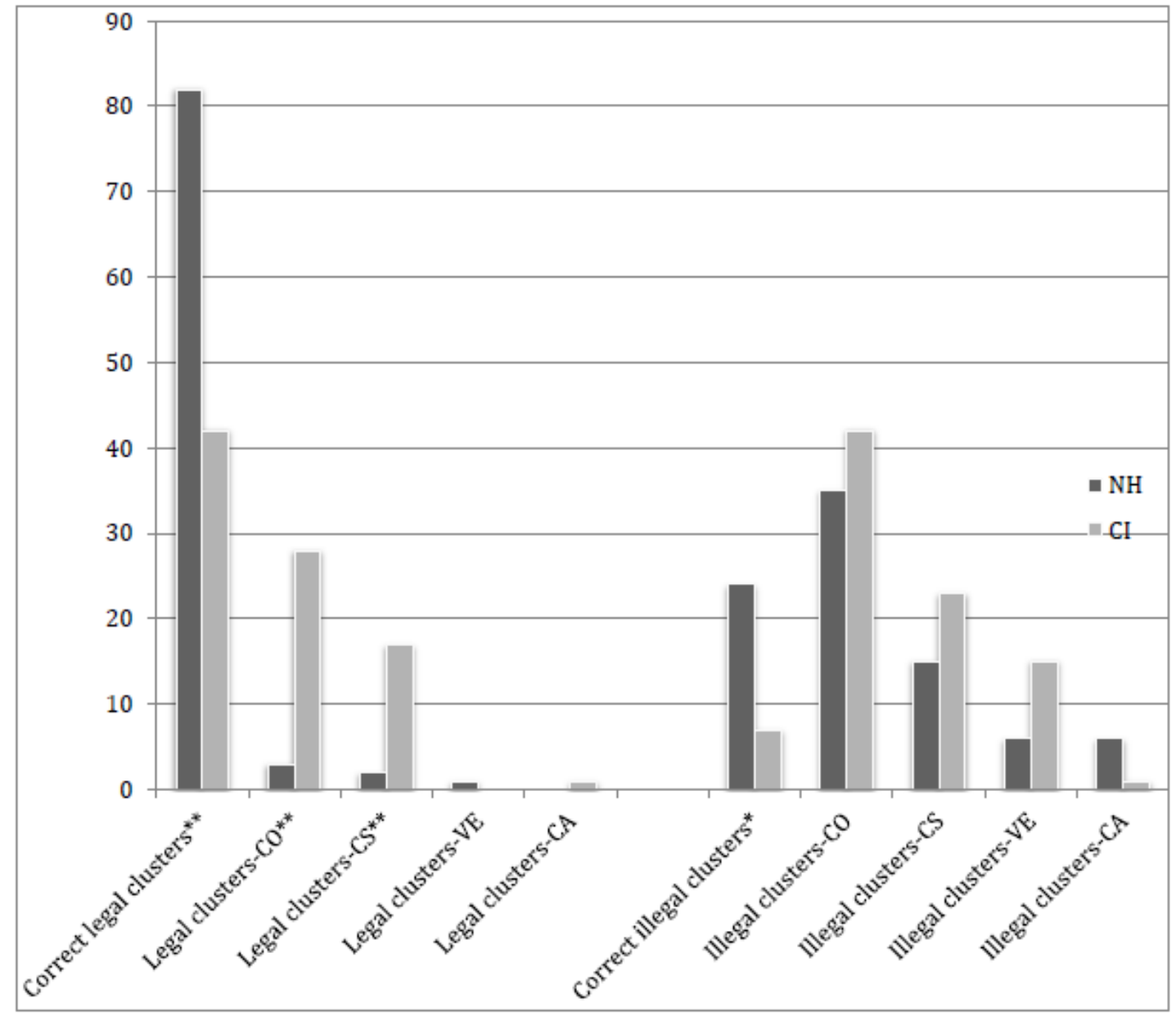

Figure 1. Number of correctly reproduced legal consonant clusters ( $\max =88$, leftmost bar), and illegal consonant clusters ( $\max =88$, bar $\mathrm{nr}$ six) followed by number of consonant omissions (CO), consonant substitutions (CS), vowel epenthesis (VE), and consonant additions (CA) in legal and illegal consonant clusters in the nonword repetition task. $\mathrm{NH}=$ normal hearing, $\mathrm{CI}=$ cochlear implants, ${ }^{*} *=p<.001,{ }^{*} p<=.05$.

In sum, children with $\mathrm{NH}$ outperformed children with $\mathrm{CI}$ on the majority of aspects of the nonword repetition task. Exceptions were found on repetitions of illegal consonant clusters where equal performance was observed in three out of four categories. Children with CI made $95 \%$ of the syllable omissions and $80 \%$ of these were made in pre-stressed position. Further, children with CI made more than $70 \%$ of all syllable insertions. For all children, insertions occurred more frequently in nonwords with illegal clusters compared to nonwords with no clusters or with legal clusters. 
Nonword decoding

Overall group comparisons

There was no significant difference between children with $\mathrm{NH}$ and children with CI on nonword decoding as for whole words correct, phonemes correct and trials, (see Table 6). The only significant difference was found for decoding errors. Children with CI made significantly more errors out of their total nonword decoding trials compared to the NH children; CI ( $M d n=$ $58.3 \%)$ vs. NH $(M d n=32.8 \%), \mathrm{z}=-2.00, p<.05, r=.47$. Two children, one child with CI (child 10) and one of the NH children (child 8) were unable to decode any nonword (thus getting a score of 0 ).

\begin{tabular}{|c|c|c|c|}
\hline & $\mathrm{NH}$ & $\mathrm{CI}$ & Sig. \\
\hline Whole words & $7.9(0-41.3)$ & $9.5(0-28.6)$ & n.s. \\
\hline Phonemes & $5.8(0-31.1)$ & $8.1(0-20.1)$ & D.s. \\
\hline Trials & $12.7(0-46.8)$ & $19.8(0-47.5)$ & D. \\
\hline Errors & $32.8(0-59.1)$ & $58.3(0-81.8)$ & $<.05$ \\
\hline
\end{tabular}

Note: TOWRE $=$ The Test Of Word Reading Efficiency, $\mathrm{NH}=$ normal hearing, $\mathrm{CI}=$ cochlear implants.

Cluster analysis

Decoding proficiency of nonwords without clusters

The children with NH $(n=10)$ reached a median of $73 \%$ correctly decoded nonwords without clusters compared to children with CI $(n=10)$ who reached a median of $38 \%$. This did not represent a statistically significant difference $(p=.14)$.

Decoding proficiency of nonwords with clusters

In total nine of the children ( $\mathrm{NH}, n=4, \mathrm{CI}, n=5)$ reached sufficiently far in TOWRE to attempt to read nonwords with clusters. The children with $\mathrm{NH}$ achieved a median of $89 \%$ correctly 
decoded clusters. The children with CI achieved a median of $50 \%$ correctly decoded clusters. This did not represent a statistically significant difference $(p=.19)$.

Nonword decoding strategies

Figure 2 shows the number of phoneme insertions, phoneme deletions, phoneme substitutions and lexicalisations of nonwords in the nonword-decoding task. In children with CI, the following decoding categories showed a higher occurrence than in $\mathrm{NH}$ children; phoneme deletions $(\mathrm{NH}=1 ; \mathrm{CI}=22)$, phoneme substitutions $(\mathrm{NH}=21 ; \mathrm{CI}=44)$, and lexicalisations $(\mathrm{NH}=3 ; \mathrm{CI}=17)$. Only phoneme deletions represented a statistically significant difference, children with CI deleting more phonemes; $\mathrm{NH}(M d n=.00)$ vs. $\mathrm{CI}(M d n=1.00), \mathrm{z}=2.67, p<$ $.05, r=.57$. Phoneme insertions and substitutions were equally distributed in the two groups. Lexicalisations of nonwords were made by two children with $\mathrm{NH}$ (child 2 and 10) and by six children with CI.

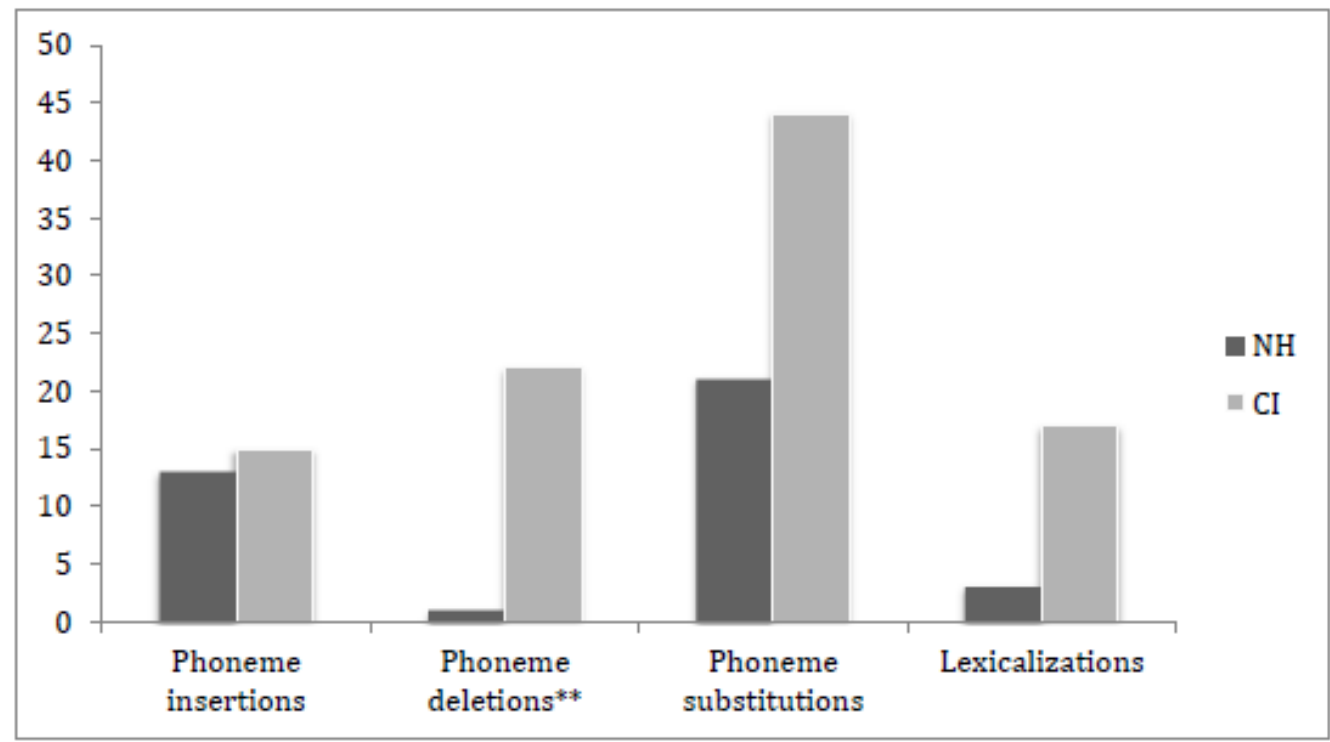

Figure 2. Nonword decoding errors in TOWRE; number of phoneme insertions, phoneme deletions, phoneme substitutions and lexicalisations in children with normal hearing $(\mathrm{NH})$ and children with bilateral cochlear implants (CI). TOWRE = the Test Of Word Reading Efficiency (TOWRE; Torgesen, Wagner \& Rashotte, 1999, Swedish version by Byrne et al., 2009), $* *=p<.001$

In sum, there was no significant difference between nonword decoding by children with $\mathrm{NH}$ and children with CI in the majority of analyses (whole words correct, phonemes correct, trials 
and decoding proficiency of nonwords with or without clusters). However, an analysis of the children's nonword decoding strategies demonstrated that children with CI made significantly more nonword decoding errors in relation to nonword decoding trials than did the NH children. Additionally, the error decoding analysis revealed that one of the error-decoding categories, phoneme deletions, occurred significantly more often in children with CI.

\section{Correlation analyses}

\section{Nonword decoding and Nonword repetition}

In children with $\mathrm{NH}$, nonword decoding (whole words correct) was significantly correlated with eight out of twelve measures of NWR. Nonword decoding (phonemes correct and trials) showed the same pattern of significant correlations in six of the measures of NWR with similar strengths in relationship, see Table 7.

In the subsequent cluster analysis, all nonword-decoding measures (whole words correct, phonemes correct, and trials) showed the same significant correlations with cluster repetition with similar strengths in relationship. The significant correlations were with legal and illegal clusters correct (positive correlations) and with consonant omissions in illegal clusters (negative correlation), see Table 8.

In children with CI, nonword decoding (whole words correct) showed one significant correlation with NWR, namely with consonant omissions in legal consonant clusters, $r s=-.66$, $p<.05$. No other significant correlations were observed, see Table 7 and 8 . 
Table 7. Correlation analysis for nonword decoding and nonword repetition in $\mathrm{NH}$ children $(\mathrm{N}=11)$ and children with bilateral $\mathrm{CI}(\mathrm{N}=11)$

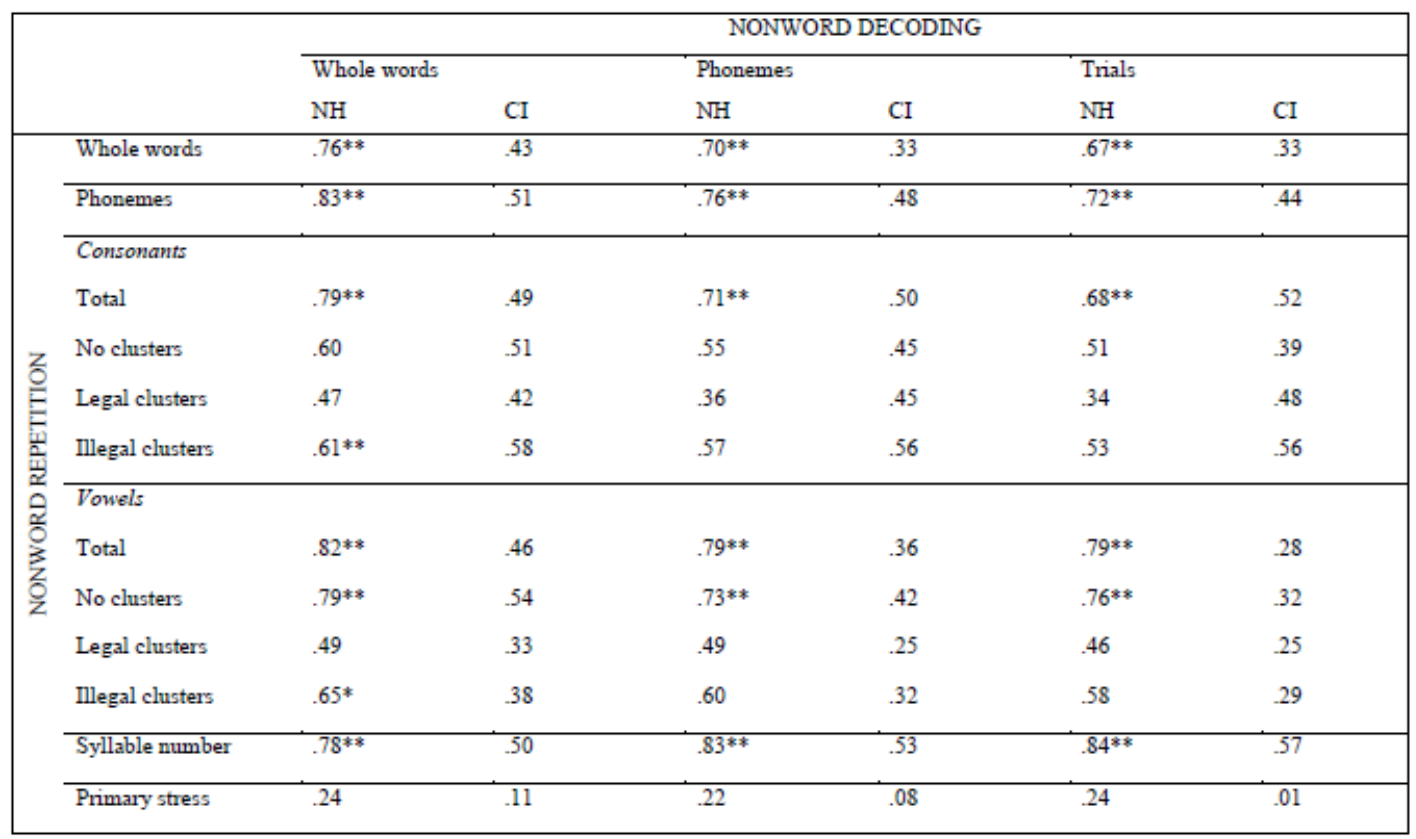

Note: $\mathrm{NH}=$ normal hearing, $\mathrm{CI}=$ cochlear implants, $*=p<.05, * *=p<.01$

Table 8. Correlation analysis for nonword decoding and cluster repetition in nonwords in children with $\mathrm{NH}(\mathrm{N}=11)$ and children with $\mathrm{CI}(\mathrm{N}=11)$

\begin{tabular}{|c|c|c|c|c|c|c|c|}
\hline & \multicolumn{6}{|c|}{ NONWORD DECODING } \\
\hline & & \multicolumn{2}{|c|}{ Whole words } & \multicolumn{2}{|c|}{ Phonemes } & \multicolumn{2}{|l|}{ Trials } \\
\hline & & $\mathrm{NH}$ & $\mathrm{CI}$ & $\mathrm{NH}$ & $\mathrm{CI}$ & $\mathrm{NH}$ & $\mathrm{CI}$ \\
\hline \multirow{12}{*}{ 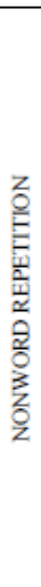 } & Legal clusters & & & & & & \\
\hline & Percent correct & $.78^{* *}$ & .34 & $.77^{* *}$ & .35 & $.78 * *$ & .31 \\
\hline & Consonant omissions & -.55 & $-.66^{*}$ & -.51 & -.59 & -.55 & -.40 \\
\hline & Consonant substitutions & -.45 & .03 & -.50 & -.02 & -.45 & -.08 \\
\hline & Vowel epenthesis & -.45 & . & -.40 & . & -.45 & . \\
\hline & Consonant additions & . & .00 & . & .20 & . & .50 \\
\hline & Illegal clusters & & & & & & \\
\hline & Percent conrect & $.85^{* *}$ & .05 & $.88^{* *}$ & -.01 & $.85^{* *}$ & -.01 \\
\hline & Consonant omissions & $-.67 *$ & .19 & $-.74^{* *}$ & .35 & $-.74 * *$ & .48 \\
\hline & Consonant substitutions & -.18 & .25 & -.08 & .14 & -.09 & .12 \\
\hline & Vowel epenthesis & -.16 & -.33 & -.18 & -.33 & -.17 & -.41 \\
\hline & Consonant additions & .54 & .10 & .59 & .00 & .56 & .00 \\
\hline
\end{tabular}


Nonword decoding, demographic variables and letter knowledge

Demographic variables were age, non-verbal intelligence scores, time with CI, age at implant, and age at diagnosis.

In children with $\mathrm{NH}$, nonword decoding (whole words correct and phonemes correct) was significantly correlated only with age $(r s=.74, p<.05$ vs. $r s=.80, p<.01)$. No significant correlation with letter knowledge was observed.

In children with CI, nonword decoding (whole words correct and phonemes correct) did not show any significant correlation with any of the demographic variables, but both measures were significantly correlated with letter knowledge ( $r s=.76, p<.05$ vs. $r s=.84, p<.05)$.

\section{Discussion}

The first aim of the present study was to examine segmental and suprasegmental characteristics in nonword repetition in eleven children with $\mathrm{NH}$ and eleven children with bilateral CI with a mean age of 6.5 years. The results showed that $\mathrm{NH}$ children outperformed children with $\mathrm{CI}$ on all aspect of nonword repetition. The largest difference between the groups was found for whole words correct. Here, NH children reached a median of 54\% correct compared to the children with CI who reached a median of $4.2 \%$ correct. This implies that repeating completely novel words after a single auditory-only presentation without making any alterations of the phonological structure is extremely challenging for children with CI (Dillon et al., 2004).

Both groups generally reproduced vowels better than consonants in the nonwords, suggesting a perceptual bias, namely the higher intensity of vowels make them easier to perceive and reproduce (Cole \& Flexer, 2011). Although consonants in general, as measured by percent consonants correct, were more difficult to reproduce, the children with CI in the present study had slightly better scores (median 53\%) than the children with CI in a number of similar studies. For example, compared to the study by Wass et al. (2008), using the same set of nonwords in Swedish-speaking children, a median score of 39\% was reported. Moreover, in the study by Dillon et al. (2004), studying English-speaking children, lower scores were reported (39\%, only mean scores available). Finally, Ibertsson et al. (2009) studying Swedish-speaking children reported lower scores (35\%, only mean scores available). In the latter two studies, the authors used other sets of nonwords ( 20 vs. 24 items, 2-5 syllables long, with the same amount of clusters, but only legal). It is important to note that at least two demographic factors differed between these three studies (Dillon et al., 2004; Ibertsson et al., 2008 and Wass et al., 2008) and the present one. First, age at implant, the children in the studies by Ibertsson et al. and Wass 
et al. got their implants activated at an average age of 45 months/30 months, compared to 20 months in the present study. Second, the mean elapsed time between age at diagnosis and age at implant was shorter for the children in the present study (10 months) than in the study by Dillon et al. (36 months, 2004). A large number of studies show that early implantation and a short duration of deafness affect phonological development positively in children with CI (Connor, Craig, Raudenbush, Heavner, \& Zwolan, 2006; Ertmer, Kloiber, Jung, Kirleis, \& Bradford, 2012; Geers, Tobey, Moog, \& Brenner, 2008; James, Rajput, Brinton, \& Goswami, 2008). Furthermore, another factor differed between these groups and the present one, namely all the children in the present study had received an intensive computer-assisted reading intervention with a phonics approach for four weeks right before testing (Nakeva von Mentzer et al., 2013, 2014). This latter observation could be interpreted in two possible ways. First, the children in the present study may have benefitted from the phonics training which in the computer-based program explicitly focuses on phoneme differentiation (Lyytinen et al., 2009). This means that the phoneme-grapheme correspondence training possibly generalized to consonant repetition proficiency in the nonword repetition task. Second, it can not be ruled out that this could be a test-retest effect, similar to the one reported in children with SLI (Gray, 2003).

Relatively better performance on suprasegmental properties compared to segmental properties (consonants) was observed in children with CI. On correct primary stress for example, children with CI reached their highest score and showed a relatively more homogenous performance level compared to other measures of NWR. The loss of segmental detail may indicate that segments are more difficult to reproduce than suprasegmental properties. This corroborates findings in previous studies on relative suprasegmental strength in nonword repetition in children with CI (Carter et al., 2002; Ibertsson et al., 2008). Results are also compatible with perceptually based models of early word production and representation in NH children (Echols, 1993) and can be interpreted in line with more linguistically oriented models of speech production (Gerken, 1994). Carter et al. (2002) propose a separation of segmental and suprasegmental tiers in children with CI, suggesting that the encoding of new words may be accomplished on the suprasegmental tier. Echols (1993) suggests that stress patterns may be more perceptually salient than segmental features and accordingly may be a prominent feature in children's early word representations. Consequently, perceptual advantages of suprasegmental information are most likely due to the signal properties of the CI that favour the perception of the prosodic envelope (Moore, 2008). 
Suprasegmental analyses of stress patterns must be anchored in the characteristics of the ambient language. Most above-mentioned studies are based on English-speaking children whereas the present study is based on Swedish-speaking children. Word stress in English, as well as in Swedish, has a trochaic bias and, in early language acquisition, weak syllables are often omitted in pre-stressed positions (Leonard, 2000; Reuterskiöld-Wagner, Sahlén \& Nyman, 2005). When children's syllable omissions in nonwords were analysed, children with CI were found to make the majority of them, and the stress pattern affected the occurrence of omissions in the children with CI. The findings in the present study showed that weak syllable omissions were almost twice as common in pre-stressed positions than in post-stressed position in children with CI. This suggests a trochaic bias, not only in language acquisition, but also in NWR in Swedish children with CI, in line with the findings in English-speaking children with CI (Carter et al., 2002).

The participating children's ambient language also seemed to influence insertions. Insertions were mostly made in nonwords with illegal clusters for all children. The interpretation is that phonotactic knowledge influenced performance. In the present study the children inserted a vowel in between the consonants in the phonotactically illegal cluster to adapt it to Swedish phonotactic rules, as also has been reported for English-speaking children by Pitt (1998) and Vihman, DePaolis, and Davis (1998). This is also a process that occurs in consonant cluster acquisition in spontaneous speech in typically developing Swedish children (Nettelbladt, 2007). The analysis showed that the three children with CI who made the majority of the omissions and insertions were comparably older when they received their CI than children with CI who made fewer omissions and insertions. Further, the children who made more omissions and insertions had had a shorter time with CI at the time of testing. This suggests that demographic factors, such as duration of implant use, strongly influence the ease with which children with CI perceive and produce new word shapes (Havy, Nazzi \& Bertoncini, 2013).

The last aspect of nonword repetition that was investigated, which provide novel information to this area revealed that children with CI made significantly more consonant omissions and consonant substitution when repeating legal clusters in the nonwords as compared to the $\mathrm{NH}$ children. Here, the children with NH showed floor effects, that is, hardly any omissions or substitutions occurred. Thus, for $\mathrm{NH}$ children 6.5 years of age with typical language development repeating legal consonant clusters with two or three consonants in nonwords seemed not particularly demanding. This supports the findings of Nettelbladt (2007) that in Swedish typically developing children consonant clusters are established in spontaneous speech between 4-6 years of age. For children with CI however, reproducing legal consonant clusters 
in nonwords was challenging for almost all of them, even though exceptions were found. For example, child 3 and 6 correctly repeated $75 \%$ vs. $100 \%$ of the legal clusters correct respectively.

Group comparisons of children's nonword decoding ability revealed no significant differences between groups in nonword decoding, as was the case for whole words correctly decoded and phonemes correctly decoded as well as for nonword decoding trials. Additionally, no significant difference was found in the decoding of transparent nonwords with or without clusters. However, the subsequent analysis of children's nonword decoding strategies showed a statistically significant difference between children with $\mathrm{NH}$ and children with CI, thus, a higher percentage of nonword decoding errors in relation to nonword decoding trials in the latter group. This means that the nonword decoding ability in the children with CI at the surface seemed as efficient as in the NH children (as has been previously interpreted by Dillon et al., 2001; 2006). Only when decoding errors were analysed in relation to nonword decoding trials, less precise decoding skills were revealed. The error decoding analysis showed that children with CI made far more phoneme deletions in decoding than $\mathrm{NH}$ children. These results may suggest that less fine-grained phonological processing skills in children with CI may hamper the use of the phonological route, explicitly used in nonword decoding (Nakeva von Mentzer et al., 2014). Similar conclusions were recently drawn in a study of reading and spelling skills in children with mild to moderate hearing loss (Park et al., 2013).

As for the association between nonword decoding and nonword repetition, children with $\mathrm{NH}$ showed significant correlations between nonword decoding (all measures) and the majority of aspects in nonword repetition. In children with CI nonword decoding (whole words correct) was significantly and negatively correlated only with one aspect of nonword repetition, which was consonant omissions in nonwords with legal clusters. Thus, the ability to reproduce finegrained aspects of phonology, specifically consonant clusters that follow the phonotactic rules of the ambient language was associated with a higher nonword decoding proficiency. Using fine-grained units have for long been acknowledged as particularly important in the decoding of unfamiliar items, as nonwords (Stanovich, 2000). The absence of further significant correlations between nonword decoding and nonword repetition in children with CI as opposed to children with $\mathrm{NH}$ in the present study, might indicate that these children to a lesser degree involve phonological processing skills in phonological decoding. One interpretation is that less stable phonological processing skills might lead to more guessing oriented decoding strategies, The trend towards more lexicalisations in nonword decoding in children with CI, might be seen as evidence for this, but more studies with larger samples are needed to support this finding. 
Age was significantly correlated with nonword decoding in children with $\mathrm{NH}$ but no demographic variable came out significant in children with CI. However, letter knowledge did. This result acknowledges the importance of phonological processing skills and letter knowledge in decoding, not only in children with NH (Hulme et al., 2012) but also in DHH children using CI.

\section{Future perspectives}

The findings relating to nonword repetition and associations to nonword decoding in children with CI give several possible clinical implications. For example, phonological training should aim to improve awareness and production of consonant clusters and syllable structure of words. In this way, positive effects on phonological awareness skills will follow, as children's phonological representations are improved. Additionally, letter knowledge exercises should not be overlooked since letters act as visual support for acoustically elusive elements in the speech signal. The present explorative study should be seen as a methodological contribution. It shows, that undertaking a more detailed phonological analysis in nonword repetition and nonword decoding, including segmental, suprasegmental, clusters and errors, more precise information is obtained for phonological processing skills and decoding strategies in this population. Since the present sample is small, group results should be treated with great caution.

More thorough and descriptive work on phonological skills in speech production and decoding in children with CI is needed to shed light on reading strategies in this population.

\section{Acknowledgements}

This research was funded by The Swedish Research Council for Working Life and Social Sciences, the Linneaus Centers HEAD at Linköping University, and CCL -Cognition, Communication and Learning at Lund University. We acknowledge all the children and parents participating in the study and their teachers. We thank Jonas Lindsjö, Lena Asker-Árnason, Lund University, and Anna Ericson, Stockholm University for their assistance in the datacollection. We thank Rachel Ellis, Linköping University for assistance in proofreading.

Declaration of Interest: The authors report no conflict of interest. 


\section{References}

Adi-Bensaid, L., \& Ben-David, A. (2010). Typical acquisition by atypical children: Initial consonant cluster acquisition by Israeli Hebrew-acquiring children with cochlear implants. Clinical Linguistics and Phonetics, 24(10), 771-794. doi: 10.3109/02699206.2010.498932

Aro, M., Aro, T., Ahonen, T., Rasanen, T., Hietala, A., \& Lyytinen, H. (1999). The development of phonological abilities and their relation to reading acquisition: case studies of six Finnish children. Journal of Learning Disability, 32(5), 457-463, 478.

Asker- Árnason, L., Wass, M., Ibertsson, T., Lyxell, B., \& Sahlen, B. (2007). The relationship between reading comprehension, working memory and language in children with cochlear implants. Acta Neuropsychologica, 5(4), 163-186.

Asker-Árnason, L., Wass, M., Gustavsson, F., \& Sahlén, B. (submitted, 2014). Reading comprehension and working memory in children with hearing impairment and cochlear implants and hearing aids.

Baddeley, A. (1998). Working memory. Comptes Rendus de l'Académie des Sciences - Series III - Sciences de la Vie, 321(2-3), 167-173.

Bosworth, J. (1838). A Dictionary of the Anglo-Saxon Language. Retrieved 2014-06-19 from http://books.google.se/books?id=oH9FAAAAcAAJ\&printsec=frontcover\&dq=A+Dict ionary+of +the+Anglo-

Saxon+Language \&hl=sv\&sa=X\&ei=28eVU8KNNsu7ygPPvYHYCg\&ved=0CDMQ6 AEwAQ $\quad-\quad \mathrm{v}=$ onepage $\& \mathrm{q}=\mathrm{A} \% 20$ Dictionary\%20of\%20the\%20AngloSaxon $\% 20$ Language $\& \mathrm{f}=$ false

Byrne, B., Coventry, W. L., Olson, R. K., Samuelsson, S., Corley, R., Willcutt, E. G., Wadsworth, S., \& Defries, J. C. (2009). Genetic and Environmental Influences on Aspects of Literacy and Language in Early Childhood: Continuity and Change from Preschool to Grade 2. Journal of Neurolinguistics, 22(3), 219-236. doi: 10.1016/j.jneuroling.2008.09.003

Carter, A. K., Dillon, C. M., \& Pisoni, D. B. (2002). Imitation of nonwords by hearing impaired children with cochlear implants: suprasegmental analyses. Clinical Linguistics and Phonetics, 16(8), 619-638.

Carter, A. K., \& Gerken, L. (2003). Similarities in weak syllable omissions between children with specific language impairment and normally developing language: a preliminary report. Journal of Communication Disorders, 36(2), 165-179. 
Casserly, E. D., \& Pisoni, D. B. (2013). Nonword repetition as a predictor of long-term speech and language skills in children with cochlear implants. Otology Neurotology, 34(3), 460-470. doi: 10.1097/MAO.0b013e3182868340

Coady, J. A., \& Evans, J. L. (2008). Uses and interpretations of non-word repetition tasks in children with and without specific language impairments (SLI). International Journal of Language \& Communication Disorders, 43(1), 1-40. doi: $10.1080 / 13682820601116485$

Conant, L. L., Liebenthal, E., Desai, A., \& Binder, J. R. (2013). FMRI of phonemic perception and its relationship to reading development in elementary- to middle-school-age children. Neuroimage. doi: 10.1016/j.neuroimage.2013.11.055

Connor, C. M., Craig, H. K., Raudenbush, S. W., Heavner, K., \& Zwolan, T. A. (2006). The age at which young deaf children receive cochlear implants and their vocabulary and speech-production growth: is there an added value for early implantation? Ear and Hearing, 27(6), 628-644. doi: 10.1097/01.aud.0000240640.59205.42

Dillon, C. M., Cleary, M., Pisoni, D. B., \& Carter, A. K. (2004). Imitation of nonwords by hearing - impaired children with cochlear implants: segmental analyses. Clinical Linguistics and Phonetics, 18(1), 39-55. doi: doi=10.1080\%2F0269920031000151669

Dillon, C. M., \& Pisoni, D. B. (2001). Nonword repetition and reading in deaf children with cochlear implants. International Congress Series, 1273, 304-307. doi: 10.1016/j.ics.2004.07.042

Dillon, C. M., \& Pisoni, D. B. (2006). Non word Repetition and Reading Skills in Children Who Are Deaf and Have Cochlear Implants. Volta Review, 106(2), 121-145.

Echols, C. H. (1993). A perceptually-based model of children's earliest productions. Cognition, 46(3), 245-296.

Ertmer, D. J., Kloiber, D. T., Jung, J., Kirleis, K. C., \& Bradford, D. (2012). Consonant production accuracy in young cochlear implant recipients: developmental sound classes and word position effects. American Journal of Speech-Language Pathology, 21(4), 342-353. doi: 10.1044/1058-0360(2012/11-0118

Frith, U. (1985). Beneath the surface of developmental dyslexia, In Surface dyslexia, chapter 32 (J. M. KE Patterson, M. Coltheart Ed.). London: Erlbaum.

Gathercole, S.E. (2006). Nonword repetition and word learning: The nature of the relationship. Applied Psycholinguistics,, 27(4), 513-543. doi: DOI 10.1017/S0142716406060383 
Geers, A. (2003). Predictors of reading skill development in children with early cochlear implantation. Ear and Hearing, 24(1 Suppl), 59S-68S. doi: 10.1097/01.AUD.0000051690.43989.5D

Geers, A., Tobey, E., Moog, J., \& Brenner, C. (2008). Long-term outcomes of cochlear implantation in the preschool years: from elementary grades to high school. International Journal of Audiology, 47 Suppl 2, S21-30. doi: $10.1080 / 14992020802339167$

Gray, S. (2003). Diagnostic accuracy and test-retest reliability of nonword repetition and digit span tasks administered to preschool children with specific language impairment. Journal of Communication Disorders, (36), 129-151

Gerken, L. (1994). A metrical template account of children's weak syllable omissions from multisyllabic words. Journal of Child Language, 21(3), 565-584.

Havy, M., Nazzi, T., \& Bertoncini, J. (2013). Phonetic processing during the acquisition of new words in 3-to-6-year-old French-speaking deaf children with cochlear implants. Journal of Communication Disorders, 46(2), 181-192. doi: 10.1016/j.jcomdis.2012.12.002

Hulme, C., Bowyer-Crane, C., Carroll, J. M., Duff, F. J., \& Snowling, M. J. (2012). The causal role of phoneme awareness and letter-sound knowledge in learning to read: combining intervention studies with mediation analyses. Psychology Science, 23(6), 572-577. doi: $10.1177 / 0956797611435921$

Ibertsson, T., Willstedt-Svensson, U., Radeborg, K., \& Sahlen, B. (2008). A methodological contribution to the assessment of nonword repetition-a comparison between children with specific language impairment and hearing-impaired children with hearing aids or cochlear implants. Logopedics Phoniatrics Vocology, 33(4), 168-178. doi: $10.1080 / 14015430801945299$

James, D., Rajput, K., Brinton, J., \& Goswami, U. (2008). Phonological awareness, vocabulary, and word reading in children who use cochlear implants: does age of implantation explain individual variability in performance outcomes and growth? Journal of Deaf Studies and Deaf Education, 13(1), 117-137. doi: 10.1093/deafed/enm042

Kalnak, N., Peyrard-Janvid, M., Forssberg, H., \& Sahlen, B. (2014). Nonword repetition--a clinical marker for specific language impairment in Swedish associated with parents' language-related problems. PLoS One, 9(2), e89544. doi: 10.1371/journal.pone.0089544

Krishnan, S., Alcock, K. J., Mercure, E., Leech, R., Barker, E., Karmiloff-Smith, A., \& Dick, F. (2013). Articulating novel words: children's oromotor skills predict non-word 
repetition abilities. Journal of Speech Language and Hearing Research. doi: $10.1044 / 1092-4388(2013 / 12-0206)$

Leonard, L.B. (2000). Children with specific language impairment. A Bradford book. The MIT Press: Cambridge, Massachusetts, London, England

Lyytinen, H., Erskine, J., Kujala, J., Ojanen, E., \& Richardson, U. (2009). In search of a sciencebased application: a learning tool for reading acquisition. Scandinavian Journal of Psychology, 50(6), 668-675. doi: 10.1111/j.1467-9450.2009.00791.x

Melby-Lervåg, M., Lyster, S. A., \& Hulme, C. (2012). Phonological skills and their role in learning to read: a meta-analytic review. Psychological Bulletin, 138(2), 322-352. doi: $10.1037 / \mathrm{a} 0026744$

Moore, B. C. (2008). The role of temporal fine structure processing in pitch perception, masking, and speech perception for normal-hearing and hearing-impaired people. Journal of the Associations for Research in Otolaryngology, 9(4), 399-406. doi: $10.1007 / \mathrm{s} 10162-008-0143-\mathrm{x}$

Nakeva von Mentzer, C., Lyxell, B., Sahlen, B., Wass, M., Lindgren, M., Ors, M., Kallioinen, P., \& Uhlen, I. (2013). Computer-assisted training of phoneme-grapheme correspondence for children who are deaf and hard of hearing: Effects on phonological processing skills. International Journal of Pediatric Otorhinolaryngology, 77(12), 2049-2057. doi: 10.1016/j.ijporl.2013.10.007

Nakeva von Mentzer, C., Lyxell, B., Sahlén, B., Dahlström, Ö., Lindgren, M., Kallioinen, P., Ors, M., \& Uhlén, I. (2014). Computer assisted reading intervention with a phonics approach for children using cochlear implants or hearing aids. Scandinavian Journal of Psychology. doi: 10.1111/sjop.12149.

Nash, H. M., Hulme, C., Gooch, D., \& Snowling, M. J. (2013). Preschool language profiles of children at family risk of dyslexia: continuities with specific language impairment. The Journal of Child Psychology and Psychiatry, 54(9), 958-968. doi: 10.1111/jcpp.12091

Nettelbladt, U. (2007). Phonological development. In Språkutveckling och språkstörning hos barn (pp. 57-94). U. Nettelbladt, \& E. K. Salameh (Eds.), Lund: Studentlitteratur.

Näslund, J. C., \& Schneider, W. (1996). Kindergarten letter knowledge, phonological skills, and memory processes: relative effects on early literacy. Journal of Experimental Child Psychology, 62(1), 30-59. doi: 10.1006/jecp.1996.0021

Park, J., Lombardino, L.J., \& Ritter, M.J. (2013). Phonology matters: A comprehensive investigation of reading and spelling skills of school-age children with mild to moderate sensorineural hearing loss. American Annals of the Deaf, 158(1), 20-40. 
Pitt, M. A. (1998). Phonological processes and the perception of phonotactically illegal consonant clusters. Perception and Psychophysics, 60(6), 941-951.

Puolakanaho, A., Ahonen, T., Aro, M., Eklund, K., Leppanen, P. H., Poikkeus, A. M., Tolvanen, A., Torppa, M., \& Lyytinen, H. (2007). Very early phonological and language skills: estimating individual risk of reading disability. Journal of Child Psychology and Psychiatry, 48(9), 923-931. doi: 10.1111/j.1469-7610.2007.01763.x

Puolakanaho, A., Ahonen, T., Aro, M., Eklund, K., Leppanen, P. H., Poikkeus, A. M., Tolvanen, A., Torppa, M., \& Lyytinen, H. (2008). Developmental links of very early phonological and language skills to second grade reading outcomes: strong to accuracy but only minor to fluency. Journal of Learning Disability, 41(4), 353-370. doi: $10.1177 / 0022219407311747$

Ramus, F. (2001). Outstanding questions about phonological processing in dyslexia. Dyslexia, 7(4), 197-216. doi: 10.1002/dys.205

Ramus, F., \& Szenkovits, G. (2008). What phonological deficit? Quarterly Journal of Experimental Psychology (Hove), 61(1), 129-141. doi: 10.1080/17470210701508822

Reuterskiöld-Wagner, C., Sahlen, B., \& Nyman, A. (2005). Non-word repetition and non-word discrimination in Swedish preschool children. Clinical Linguistics \& Phonetics, 19(8), 681-699. doi: 10.1080/02699200400000343

Rispens, J., \& Baker, A. (2012). Nonword repetition: the relative contributions of phonological short-term memory and phonological representations in children with language and reading impairment. Journal of Speech Language and Hearing Research, 55(3), 683694. doi: 10.1044/1092-4388(2011/10-0263)

Sahlén, B., Reuterskiöld-Wagner, C., Nettelbladt, U., \& Radeborg, K. (1999a). Non-word repetition in children with language impairment--pitfalls and possibilities. International Journal of Language and Communication Disorders, 34(3), 337-352.

Sahlén, B., Reuterskiöld-Wagner, C., Nettelbladt, U., \& Radeborg, K. (1999b). Language comprehension and nonword repetition in children with language impairment. Clinical Linguistics and Phonetics, 13, 369-380.

Share, D. L. (1995). Phonological recoding and self-teaching: Sine qua non of reading acquisition. Cognition, 55(2), 151-218

Stanovich, Keith E. (2000). Progress in understanding reading. New York, London: The Guilford Press. 
Talcott, J. B., Witton, C., \& Stein, J. F. (2013). Probing the neurocognitive trajectories of children's reading skills. Neuropsychologia, 51(3), 472-481. doi: 10.1016/j.neuropsychologia.2012.11.016

Torgesen, J., Wagner, R., \& Rashotte, CA. (1999). A Test of Word Reading Efficiency (TOWRE). PRO-ED; Austin, Texas.

Vihman, M. M., DePaolis, R. A., \& Davis, B. L. (1998). Is there a "trochaic bias" in early word learning? Evidence from infant production in English and French. Child Development, 69(4), 935-949.

Wass, M., Ibertsson, T., Lyxell, B., Sahlen, B., Hällgren, M., Larsby, B., \& Mäki-Torkko, E. (2008). Cognitive and linguistic skills in Swedish children with cochlear implants measures of accuracy and latency as indicators of development. Scandinavian Journal of Psychology, 49(6), 559-576. doi: 10.1111/j.1467-9450.2008.00680.x

Wass, M., Lyxell, B., Sahlén, B., Asker- Árnason, L., Ibertsson, T., Mäki-Torkko, E., Hällgren, M., \& Larsby, B. (2010). Cognitive skills and reading ability in children with cochlear implants. Cochlear Implants International, 11 Suppl 1, 395-398. doi: 10.1179/146701010X12671178103751

Welcome, S.E., Leonard, C.M., \& Chiarello, C. (2010). Alternate reading strategies and variable asymmetry of the planum temporale in adult resilient readers. Brain and Language, 113(2), 73-83. doi: http://dx.doi.org/10.1016/j.bandl.2010.01.003

Yuzawa, M., \& Saito, S. (2006). The role of prosody and long-term phonological knowledge in Japanese children's nonword repetition performance. Cognitive Development, 21, 146-157. doi: doi:10.1016/j.cogdev.2006.01.003

Ziegler, J. C., Castel, C., Pech-Georgel, C., George, F., Alario, F. X., \& Perry, C. (2008). Developmental dyslexia and the dual route model of reading: simulating individual differences and subtypes. Cognition, 107(1), 151-178. doi: 10.1016/j.cognition.2007.09.004 
Appendix. Nonwords in the present study

\begin{tabular}{|c|c|}
\hline Phonetic transcription & Orthographic notation \\
\hline \multicolumn{2}{|l|}{$C V C V$} \\
\hline \multicolumn{2}{|l|}{ Three-syllable } \\
\hline 1. /'su:meta/ & 'sumetta \\
\hline 2. /'ka:simem/ & 'kasimum \\
\hline 3. /'clomoki/ & 'ellomocki \\
\hline 4. /'tølime:ro/ & 'töllimero \\
\hline 5. /salv'ta:n/ & sallo’tan \\
\hline 6. /nesu'lo:/ & nesso’lå \\
\hline \multicolumn{2}{|l|}{ Four-syllable } \\
\hline 7. /lytusa'lu:k/ & lyttosa'luk \\
\hline 8. /pu:rima'gu:1/ & purima'gol \\
\hline \multicolumn{2}{|l|}{$C C V / C C C V$} \\
\hline \multicolumn{2}{|l|}{ Three-syllable } \\
\hline 9. /'hœntpu:lə/ & 'höntpule \\
\hline 10. /'spja:bitə/ & 'spjabitte \\
\hline 11. /møjə'stra:1/ & muje'stral \\
\hline 12. /vyta'kle:/ & vytta'kle \\
\hline \multicolumn{2}{|l|}{ Four-syllable } \\
\hline 13. /'blegəsmayə/ & bläggesmange \\
\hline 14. /'dralabeli// & 'drallabelli \\
\hline 15. /getenım'flæ:r/ & gettenim'flär \\
\hline 16. /hilıpa'tru:d/ & hillipa'trud \\
\hline \multicolumn{2}{|l|}{ Violating Swedish Phonotax } \\
\hline \multicolumn{2}{|l|}{ Three-syllable } \\
\hline 17. /'tfa:rasət/ & 'tfarasset \\
\hline 18. /'tke:nema/ & 'tkenema \\
\hline 19. /scka'la:gb/ & seka’lagb \\
\hline 20. /fega'skle:/ & fuga'skle \\
\hline \multicolumn{2}{|l|}{ Four-syllable } \\
\hline 21. /'pto:kalavey/ & 'ptåkallavung \\
\hline 22. /'msta:mirakud/ & 'mstamirakud \\
\hline 23. /aguva'ta:sml/ & agova’tasml \\
\hline 24. /karatı'mi:bkl/ & karati'mibkl \\
\hline
\end{tabular}

Note: $\mathrm{C}=$ consonant, $\mathrm{V}=$ vowel 